\title{
Particle Size Studies on Tobacco Smoke*
}

\author{
by C. H. Keith
}

Celanese Fibers Company, Charlotte, North Carolina, U.S.A.

\section{INTRODUCTION}

Because of the importance of the size and concentration of tobacco smoke particles on the physiological impact of cigarette smoke, a number of articles on this subject have been published over the years $(1-8)$.

As summarized by Holmberg (8), the various techniques utilized have given a variety of results, with number median diameters ranging from 0.16 to 0.51 micrometer and mass median diameters in the range of 0.28 to 0.72 micrometer. While some of this difference can be ascribed to differences in the cigarettes tested and to the measuring technique employed, it is likely that a large part of the discrepancy stems from the variation in time elapsed during handling of the smoke prior to the size measurement. As is well known from theory and experiment, concentrated aerosols rapidly coagulate through collisions and merging of particles (9). For cigarette smoke with its unusually high particulate concentration of $1 \times 10^{\circ}$ or more particles per ml and its small particle size of 0.1 to 1.0 micrometer, this coagulation is extremely rapid and sizeable changes in these quantities can occur in fractions of a second (4). Other difficulties which can affect the results of a smoke particle size and concentration measurement are evaporation of the particles in diluting air and deposition of the particles on the walls of the collection equipment.

To avoid these problems, a method involving the instantaneous fixation of tobacco smoke as it issues from the butt end of a cigarette, followed by a rapid collection of the fixed particles, has been devised. The fixation technique, which was originally described by Peck (10), involves the reaction of the liquid particles with methyl 2-cyanoacrylate vapor to form a solid aerosol. Because the solid particles do not coalesce when they collide, any further coagulation after fixation can be observed, and the particle size distribution of the original smoke can be determined from the remaining single particles. The

\footnotetext{
- Presented at the 34th Tobacco Chemists' Research Conference, Richmond, Va., October 1980.

Received: 26th February 1981 - accepted: 8th September 1931.
}

technique of cyanoacrylate fixation has been used by Carter and Hasegawa (7) and Holmberg (8) for particle size studies and by Morie et al. (11) for studying deposits on filters. The major innovation in our work has been the fixation of smoke directly as it issues from the cigarette without intermediate handling or drying steps. Using this technique, the effects of aging on particle size and concentration have been studied for unfiltered smoke from an American-type blend. The effects of puff number and changing the blend to a tobacco substitute have also been investigated. Finally, the effects of filtration and tobacco column and filter dilution have been studied.

\section{EXPERIMENTAL}

The apparatus used for the fixation and collection of the solidified smoke particles is shown in Figure 1. A small brass collar is attached to the butt end of a cigarette to inject methyl cyanoacrylate vapor directly into the issuing smoke stream. The vapor stream is prepared at the top of the figure by sweeping dry filtered nitrogen over a small pool of monomer heated to $70^{\circ} \mathrm{C}$.

Figure 1. Apparatus.

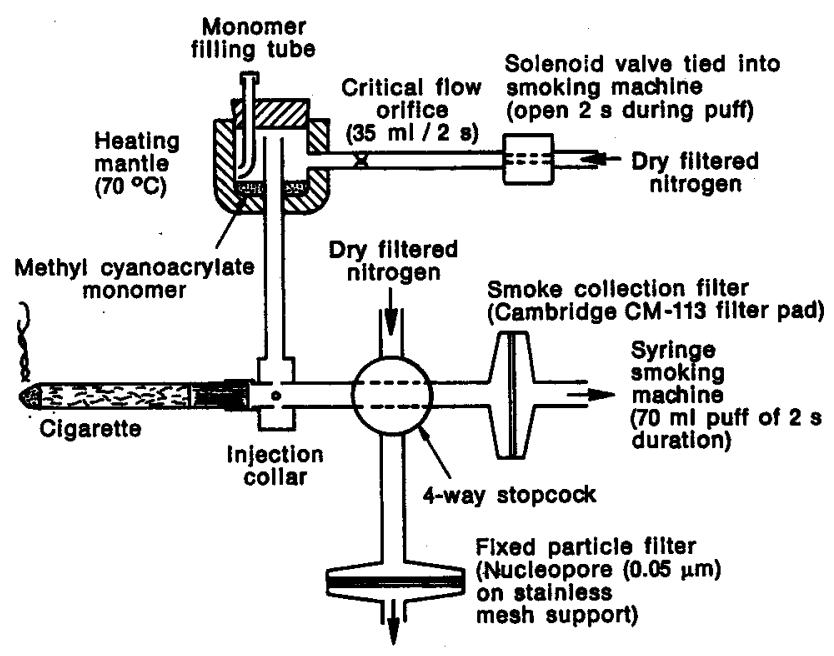


Figure 2. Photograph of fixed smoke particles $(10,000 \times)$.

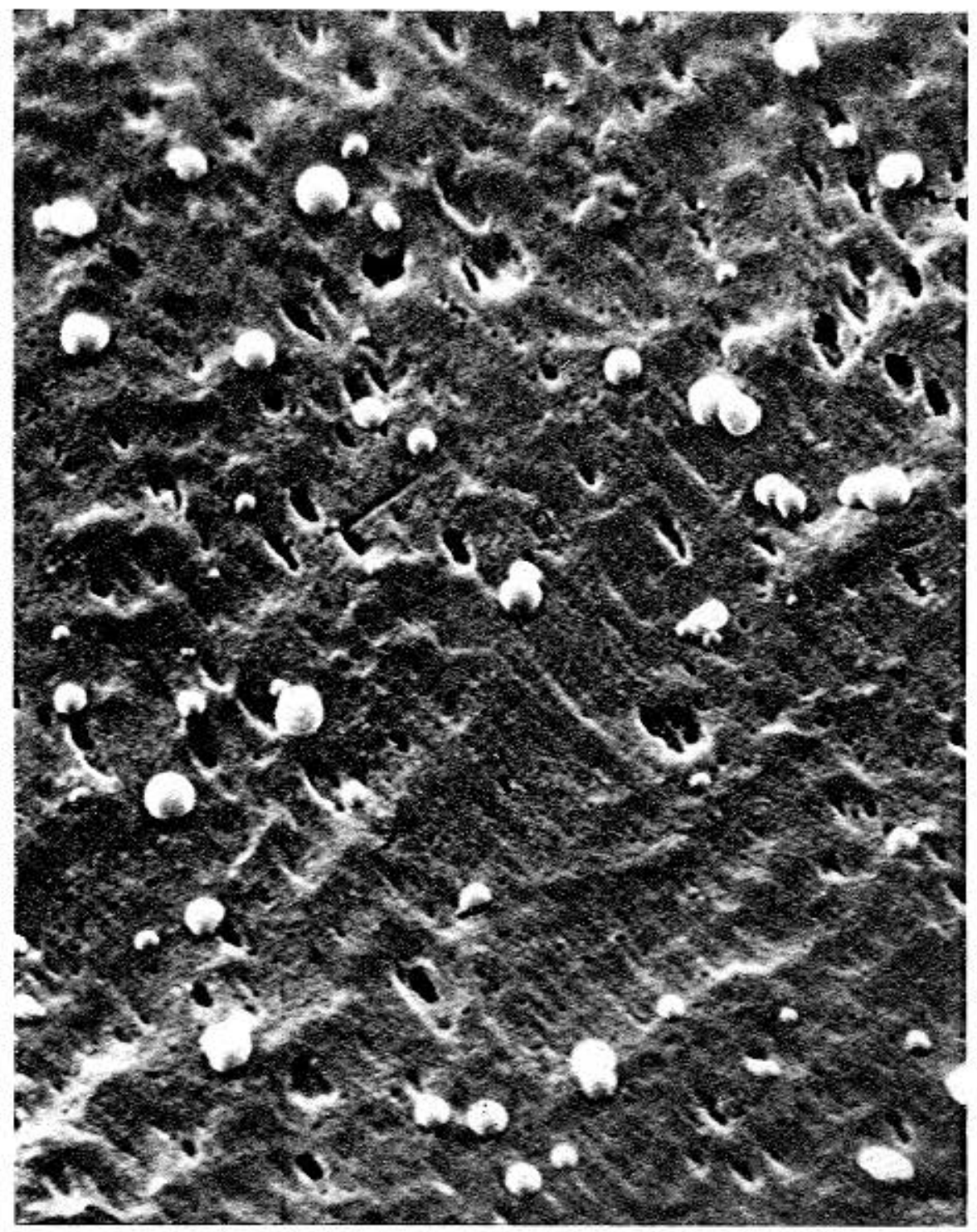

* The definitions of the various average and median diameters are as described by $F_{\text {uchs }}(12)$ :

1. Average diameter $=$

$$
\frac{\sum_{\mathrm{i}} \mathrm{d}_{\mathrm{i}} \mathrm{n}_{\mathrm{i}}}{\mathrm{n}}
$$

$=$ the arithmetic mean diameter,

where

$\mathrm{d}_{\mathrm{i}}=$ mean diameter of particles in a given interval,

$n_{i}=$ number of particles in the interval,

$\mathrm{n}=$ total number of particles.

2. Median diameter is that diameter where half of the particles have diameters greater than and half have diameters less than that diameter. These are obtained by plotting the fraction of the total number of particles less than a given diameter on a probability scale against the square root of the particle diameter. These plots are generally linear in the central region of interest. The diameter corresponding to a probability of 0.5 is considered to be the median diameter.

3. Mass average diameter $=$

$$
\frac{\sum_{\mathrm{i}} \mathrm{d}_{\mathrm{i}}^{3} \mathrm{n}_{\mathrm{i}}}{\pi}
$$

$=$ the volume or weight mean diameter.

4. Mass median diameter is that diameter where half of the total weight of the particles is contained in particles with diameters less than the indicated value. As with median diameters, these are obtained from linear probability plots of the cumulative fraction of the volume or mass against the square root of the particle diameter. The diameter corresponding to 0.5 is considered to be the mass median diameter. 
The smoking routine is such that the syringe smoking machine takes a $70 \mathrm{ml}$ puff on the cigarette and the vapor stream. By means of an orifice flow control in the vapor stream, half of this puff is vapor and half is smoke, so that a standard $35 \mathrm{ml}$ puff of two seconds duration is taken on the cigarette. Flow rate measurements using a hot air anemometer indicated that the puff drawn on the cigarette was approximately the normal bell-shaped puff obtained with a syringe smoking machine, and that the puff volume was within $0.5 \mathrm{ml}$ of the specified $35 \mathrm{ml}$ value.

The mixed and reacted smoke and vapor stream passes through an $8 \mathrm{~mm}$ inside diameter four-way stopcock and a Cambridge filter pad before entering the Filamatic smoking machine. During an actual particle size measurement, the four-way stopcock is turned $90^{\circ}$ during the middle of the puff, thereby aborting the puff and allowing a two-milliliter sample of undiluted, fixed smoke to be swept by a second nitrogen stream directly onto a Nucleopore half micron filter pad, where the particles are collected. All connections are short and straight with no change in diameter to minimize loss of particles by wall deposition.

Subsequently, the collected particles are examined by scanning electron microscopy at $10,000 \times$ magnification in a Quantimet image analysis system. Single particles, i.e. those with perimeter squared to area ratios of $\mathbf{1 3 . 8 5}$ or less, are counted and sized to provide a size distribution. Similarly, all particles are counted and the counts corrected for the presence of doublets to provide an estimate of particulate concentration. Since the number of coagulated particles after fixation is fairly low, six to seven percent of the total, corrections for triplets and higher aggregates are not necessary. Typically, a total of 1000-1500 particles are measured from six areas of the filter. Similarly blank runs with and without unlit cigarettes showed that relatively few artifact particles (less than 5) coming from the cyanoacrylate vapor are present, and that these are readily distinguishable from smoke particles by their size of two micrometers or more. Blanks utilizing air at relative humidities up to $90 \%$ also gave relatively few large particles. These excessively large particles are not included in the counts.

\section{RESULTS AND DISCUSSION}

Figure 2 shows a typical deposit of fixed smoke particles at 10,000 $\times$ magnification. The particles which range from less than 0.1 micrometer up to $0.5-0.6$ micrometer appear as hard spheres, which are present individually or in groups. The Nucleopore filter material appears as a slightly rough surface with elongated pores.

A typical size distribution is shown in Figure 3 for the fourth puff from an $85 \mathrm{~mm}$ blended, unfiltered cigarette. As has been found previously $(4,8)$ a sharply peaked narrow distribution of sizes with a median or average size of $0.2-0.21$ micrometer is observed *. Unlike most

- see facing page.
Figure 3.

Size distribution (fourth puff, $85 \mathrm{~mm}$ unflitered cigarette).

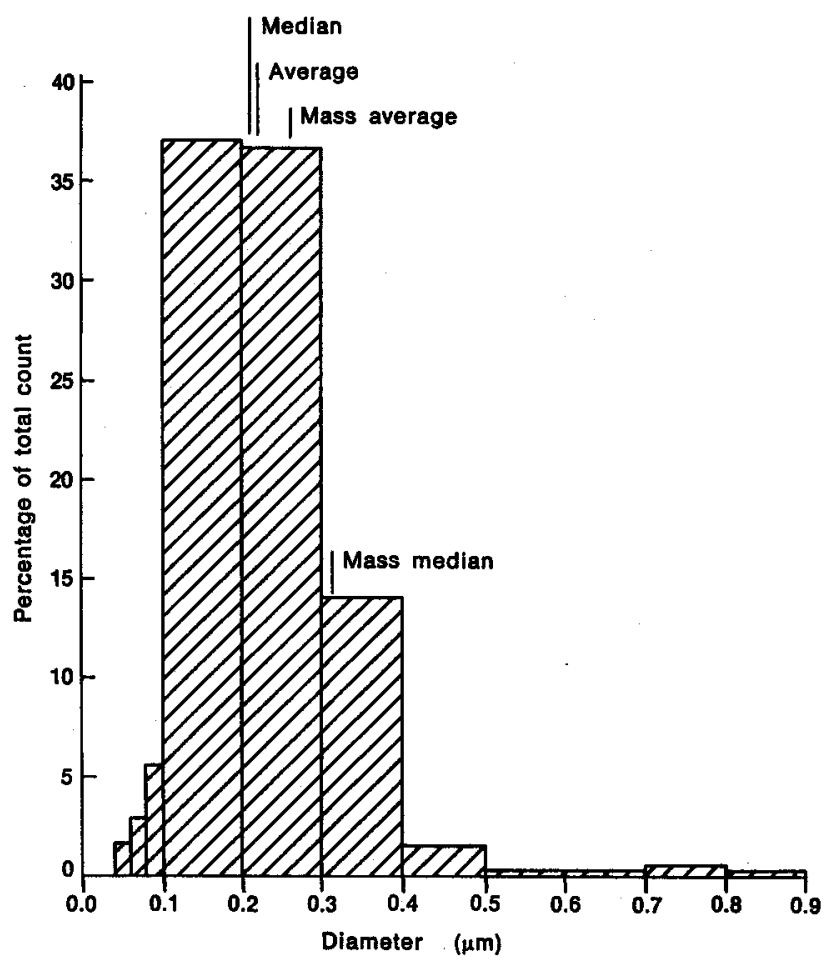

previous measurements, appreciable numbers of particles of less than 0.1 micrometer are found, ranging in some instances down to 0.02 micrometer. It is felt that this is an indication of the real situation in fresh smoke, and that these did not show up in previous work because too much coagulation had occurred before the size measurement or because these particles were below the sensitivity level of the size measuring technique.

It is also seen in this figure that relatively few particles greater than 0.5 micrometer are present. This again is an indication of the freshness of the smoke. Although many aerosols are considered to be approximately log normally distributed as discussed by Holmberg (8), this does not seem to be the case for very fresh tobacco smoke. A somewhat better fit on a probability plot is obtained by using the square root of the particle diameter as the horizontal axis. Because of this, we estimated median and mass median diameters by means of such plots, and the appropriate values are indicated in Figure $3 *$. In this distribution, it is apparent that the median and average diameters are nearly the same, indicating a number distribution which is nearly normal with only a slight skewness towards smaller particles. The mass distribution is highly skewed towards the larger particles which gives a sizeable difference between the mass average and mass median diameters.

To determine the effect of aging on the size distribution of smoke, various lengths of tubing were placed between the cigarette and the injection collar to provide differing coagulation times determined from the tube length and smoke flow rate. The results of this study are shown in Figure 4. It is readily evident that the average or median, mass average and mass median diameters are changing 
Table 1. Size distribution and particle concentrations for tobacco and tobacco supplement.

\section{Tobacco}

Average diameter $(\mu \mathrm{m})$

Median diameter $(\mu \mathrm{m})$

Mass average dlameter $(\mu \mathrm{m})$

Mass median dlameter $(\mu \mathrm{m})$

$<0.1 \mu \mathrm{m}(\%)$

$0.1-0.2 \mu \mathrm{m}(\%)$

0.2-0.3 $\mu \mathrm{m}(\%)$

0.3-0.5 $\mu \mathrm{m}(\%)$

$>0.5 \mu \mathrm{m}(\%)$

Number of particles $/ \mathrm{ml} \times 10^{-9}$

2. Tobacco supp/ement (Cytrel $\left.\left.\right|^{(}\right)$

Average diameter ( $\mu \mathrm{m})$

Median diameter $(\mu \mathrm{m})$

Mass average diameter $(\mu \mathrm{m})$

Mass medlan diameter $(\mu \mathrm{m})$

$<0.1 \mu \mathrm{m}(\%)$

0.1-0.2 $\mu \mathrm{m}(\%)$

$0.2-0.3 \mu \mathrm{m}(\%)$

$0.3-0.5 \mu \mathrm{m}(\%)$

$>0.5 \mu \mathrm{m}(\%)$

Number of particles $/ \mathrm{ml} \times 10^{-9}$

\begin{tabular}{l|l|l|l|}
\hline \multicolumn{6}{c}{ Puff number } \\
\hline 2 & 4 & 6 & 8 \\
\hline
\end{tabular}

0.211

0.199

0.249

0.321

12.7

34.2

35.0

17.9

1.2

2.70

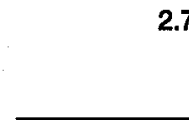

2

0.215
0.203
0.254
0.323

10.2

37.0

36.8

15.5

0.5

2.71

0.176

0.168

0.206

0.262

15.6

50.8

29.8

3.3

0.5

2.98
0.218

0.212

0.250

0.314

0.194

0.266

0.358

14.5

40.3

25.5

19.1

0.4

2.54

6 4

0.173

0.181

0.168

0.172

0.212

0.268

0.258

9.3

16.6

61.0

25.0

28.2

4.2

0.4

0.4

3.15

Table 2. Effect of filtration on smoke size distribution and concentration (4th puff, $85 \mathrm{~mm}$ cigarette).

\begin{tabular}{|c|c|c|c|c|c|}
\hline & & & & & \\
\hline & No filter & $20 \mathrm{~mm} \mathrm{CA}$ tow & $25 \mathrm{~mm} \mathrm{CA}$ tow & $30 \mathrm{~mm} \mathrm{CA}$ tow & $35 \mathrm{~mm} \mathrm{CA}$ tow \\
\hline Average diameter $(\mu \mathrm{m})$ & 0.215 & 0.211 & 0.207 & 0.211 & 0.206 \\
\hline Median diameter $(\mu \mathrm{m})$ & 0.203 & 0.205 & 0.205 & 0.205 & 0.202 \\
\hline Mass average diameter $(\mu \mathrm{m})$ & 0.254 & 0.250 & 0.241 & 0.242 & 0.240 \\
\hline Mass median diameter $(\mu \mathrm{m})$ & 0.323 & 0.303 & 0.297 & 0.297 & 0.288 \\
\hline$<0.1 \mu \mathrm{m}(\%)$ & 10.2 & 7.4 & 7.6 & 6.7 & 5.9 \\
\hline $0.1-0.2 \mu \mathrm{m}(\%)$ & 37.0 & 38.1 & 37.5 & 40.8 & 46.0 \\
\hline $0.2-0.3 \mu \mathrm{m}(\%)$ & 36.8 & 37.8 & 39.9 & 35.9 & 33.4 \\
\hline $0.3-0.5 \mu \mathrm{m}(\%)$ & 15.5 & 16.7 & 15.0 & 16.5 & 14.6 \\
\hline$>0.5 \mu \mathrm{m}(\%)$ & 0.5 & 0.0 & 0.0 & 0.0 & 0.0 \\
\hline Number of particles $/ \mathrm{ml} \times 10^{-9}$ & 2.71 & 1.77 & 1.60 & 1.33 & 1.19 \\
\hline
\end{tabular}


Figure 4. Effect of aging on particle size (fourth puff, $85 \mathrm{~mm}$ unfiltered cigarette).

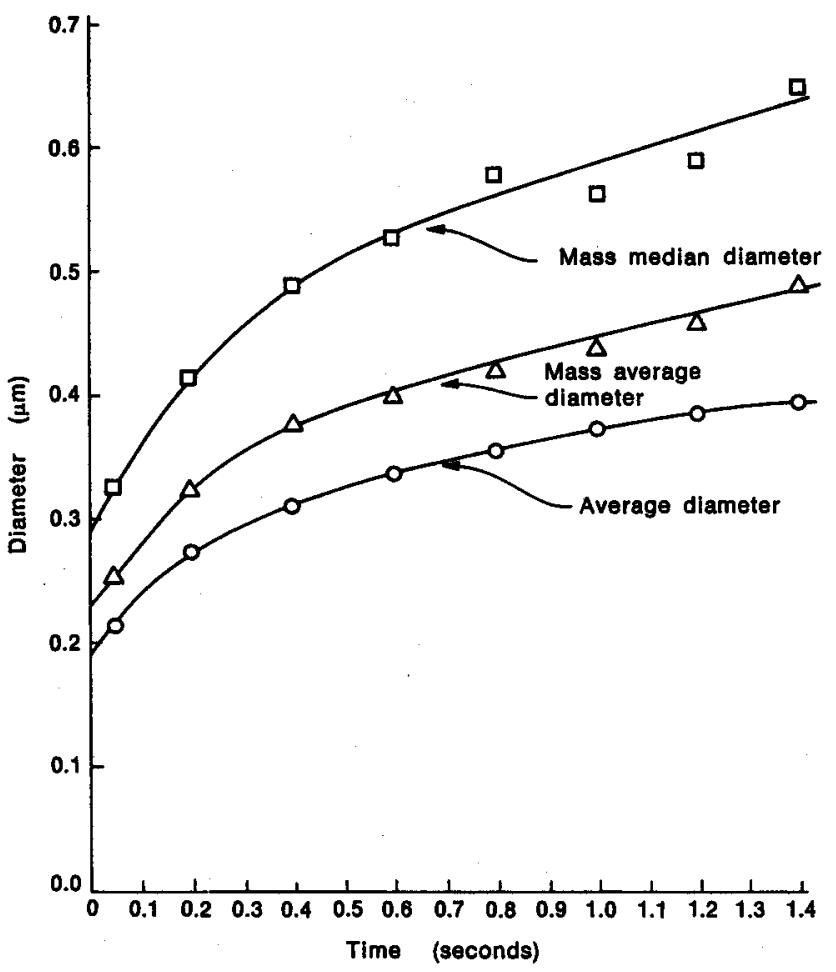

rapidly with aging time, and that within one second the particle diameters have essentially doubled. From the geometry of the injection collar we estimate that the base aging time for our measurements is 0.05 second, and that the smoke diameters have only increased by $0.03-0.04$ micrometer in this brief time. As shown in Figure 5, aging also decreases the particle concentrations (plotted as the reciprocal or volume occupied by a single particle). This is as expected from coagulation theory (9) and the slope of the curve is $12 \times 10^{-10} \mathrm{ml} / \mathrm{s}$. This compares favorably with the theoretical coagulation constant of $6 \times 10^{-10} \mathrm{ml} / \mathrm{s}$ for monodisperse $0.2 \mu \mathrm{m}$ particles in still air (13), particularly since polydispersity and flow of the smoke would both tend to increase the theoretical constant (9).

If the data on particle size and concentration as a function of aging are used to calculate the mass of smoke per $\mathrm{ml}$, a fairly constant value of $0.064 \pm 0.011 \mathrm{mg} / \mathrm{ml}$ is obtained. This compares with a fourth puff delivery for this type of cigarette of $2 \mathrm{mg} / \mathrm{puff}$ or $0.057 \mathrm{mg} / \mathrm{ml}$. The $13 \%$ higher value calculated from the particle size data may reflect the contribution of the methyl cyanoacrylate reactant to the mass of smoke. From this weight increase, it is calculated that the fixed particles can be up to 0.02 micrometer larger in diameter than the unreacted particles. If this increase in size is combined with that occurring in the unavoidable 0.05 second aging time, the average or median size of fresh unfiltered tobacco smoke would be $0.15-0.16$ micrometer, which compares well with the lowest literature values of 0.16 micrometer (5).

To investigate the effects of smoking parameters and cigarette composition on particle size, different puffs on
Flgure 5. Effect of aging on particle concentration.

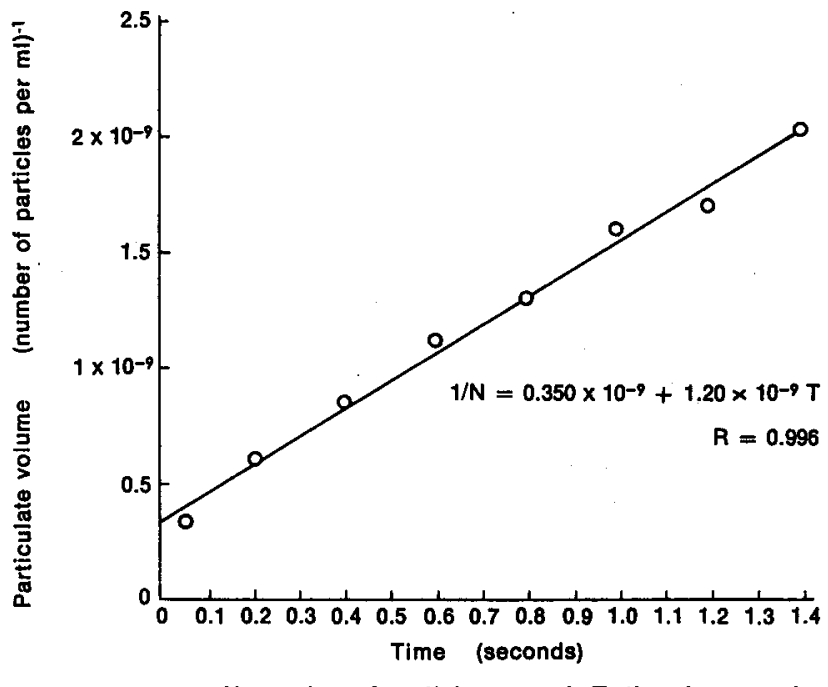

$\mathrm{N}$ : number of particles per $\mathrm{ml}, \mathrm{T}$ : time in seconds.

tobacco and tobacco supplement cigarettes were examined. The data are summarized in Table 1. As reported previously (4) and shown in these data, the size distribution is relatively stable and does not change during the smoking process; although there is an indication of a larger mass median diameter in final puffs on the cigarette. In this set of experiments, the particulate concentration does not appear to increase, which is unlike the trend reported in the literature (4).

For the mineral-filled tobacco supplement, Cytrel ${ }^{\circledR}$, the size distribution again appears to be unchanged with increasing puff number. However, the particle sizes are somewhat smaller for this material with a majority of particles less than 0.2 micrometer. This downward shift in particle size accounts for most of the $50 \%$ difference in per puff delivery for this type of cigarette. Particulate concentrations for the supplement are comparable or slightly higher than those for tobacco, and appear to show the expected upward trend with puff number.

Turning now to the effects of filtration, Table 2 summarizes the effects of 3.4 denier per filament acetate tow filters on smoke size distribution. Addition of a filter appears to reduce the average, mass average and mass median diameters of the smoke. The filter removes both large and small particles, thereby narrowing the distribution and skewing it to smaller size particles in the $0.1-0.2 \mu \mathrm{m}$ range. Increasing the length above $20 \mathrm{~mm}$ has relatively little further effect on the size distribution and only slightly heightens the effects observed with a $20 \mathrm{~mm}$ filter.

The particulate concentration of filtered smoke decreases as the length of the filter increases, as would be expected from filter efficiency results. As shown in Figure 6 , there is a good 1:1 correlation between particle removal efficiencies calculated from particulate concentrations and measured nicotine removal efficiencies for these four filters and the control filter in the upcoming dilution series. This is consistent with the view that nicotine is largely contained in the particulate phase of tobacco smoke. 
Figure 6.

Effect of acetate tow fliters on particle concentration.

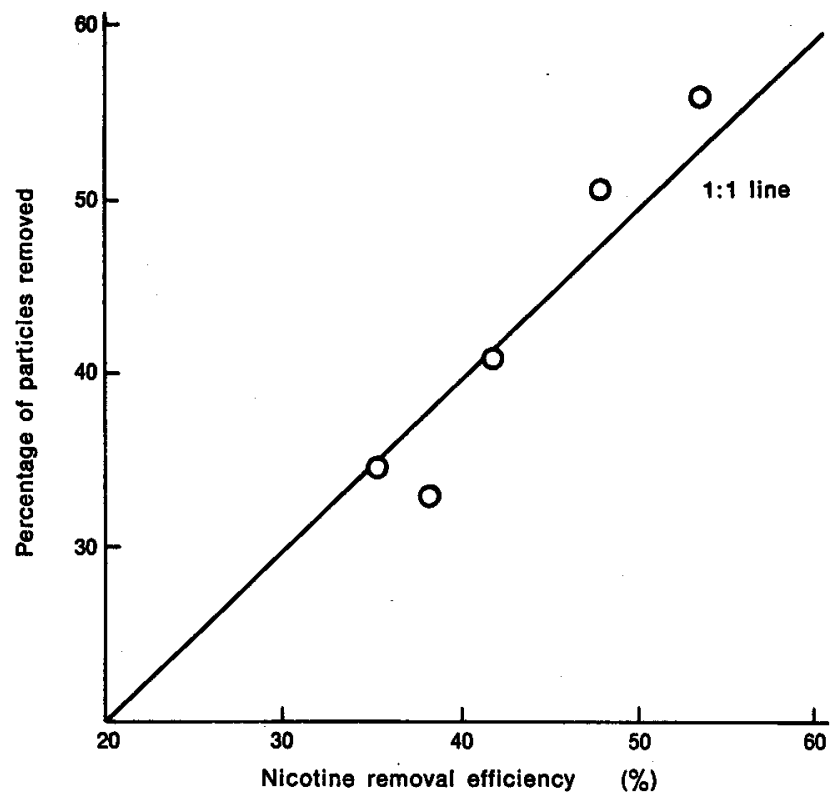

The effects of dilution on particle size and concentration were studied by examining the nine cigarettes prepared for the Coresta * dilution study several years ago (14). These cigarettes had three levels of filter dilution, $0 \%$, $26 \%$, and $56 \%$, and were wrapped in regular, porous and electrostatically perforated cigarette papers. Particle size data for the regular and porous paper samples are summarized in Table 3. Data for the perforated paper version were essentially the same as those for the porous paper samples and are not included for the sake of brevity.

In Table 3 it is apparent that the introduction of dilu-

* Coopsration Centre for Scientific Research relative to Tobacco, Paris. tion increases the average and mass average diameters of smoke particles. Mass median diameters, which are graphically estimated from probability plots, as described previously, do not show this increase as clearly; mainly because the plots were not as linear as is normally the case. In the distributions of particle sizes, there appears to be a skewing of the particles into the $0.2-0.5 \mu \mathrm{m}$ range. This is thought to occur because the addition of dilution, particularly in the filter, slows down the rate of passage of the smoke through the cigarette, thereby providing more time for coagulation of the particles. If the dilution is introduced in the tobacco column through the use of porous or perforated papers, the coagulation effect is offset by a decrease in the smoke concentration, which is not present when only filter dilution is used. For this reason, filter dilution has a greater effect in increasing smoke particle size than column dilution, as is evident in these data.

To further investigate this effect of dilution on particle size, three highly diluted, ultralow delivery commercial brands were studied. As shown in Table 4, sizeable increases in particle size were observed. All the brands had a significantly larger average particle size than the unfiltered control, and this average size increases with increasing filter dilution. The location of the dilution site also appears to play a role, as the residence time of the coagulating smoke in the filter increases as this site is moved towards the mouth end of the cigarette. Thus brand $A$, which introduces its dilution $16 \mathrm{~mm}$ from the mouth end, has smaller particles than brand $C$ which introduces its dilution $14 \mathrm{~mm}$ from the mouth end.

Smoke particle concentrations shown at the bottom of Tables 3 and 4 appear to decrease with increasing dilution levels. As shown in Figure 7, a reasonable negative correlation between particulate concentration and overall dilution level is achieved for all of the filtered ciga-

Table 3. Effect of dilution on smoke size

distribution and concentration (4th puff, $20 \mathrm{~mm}$ tow filter).

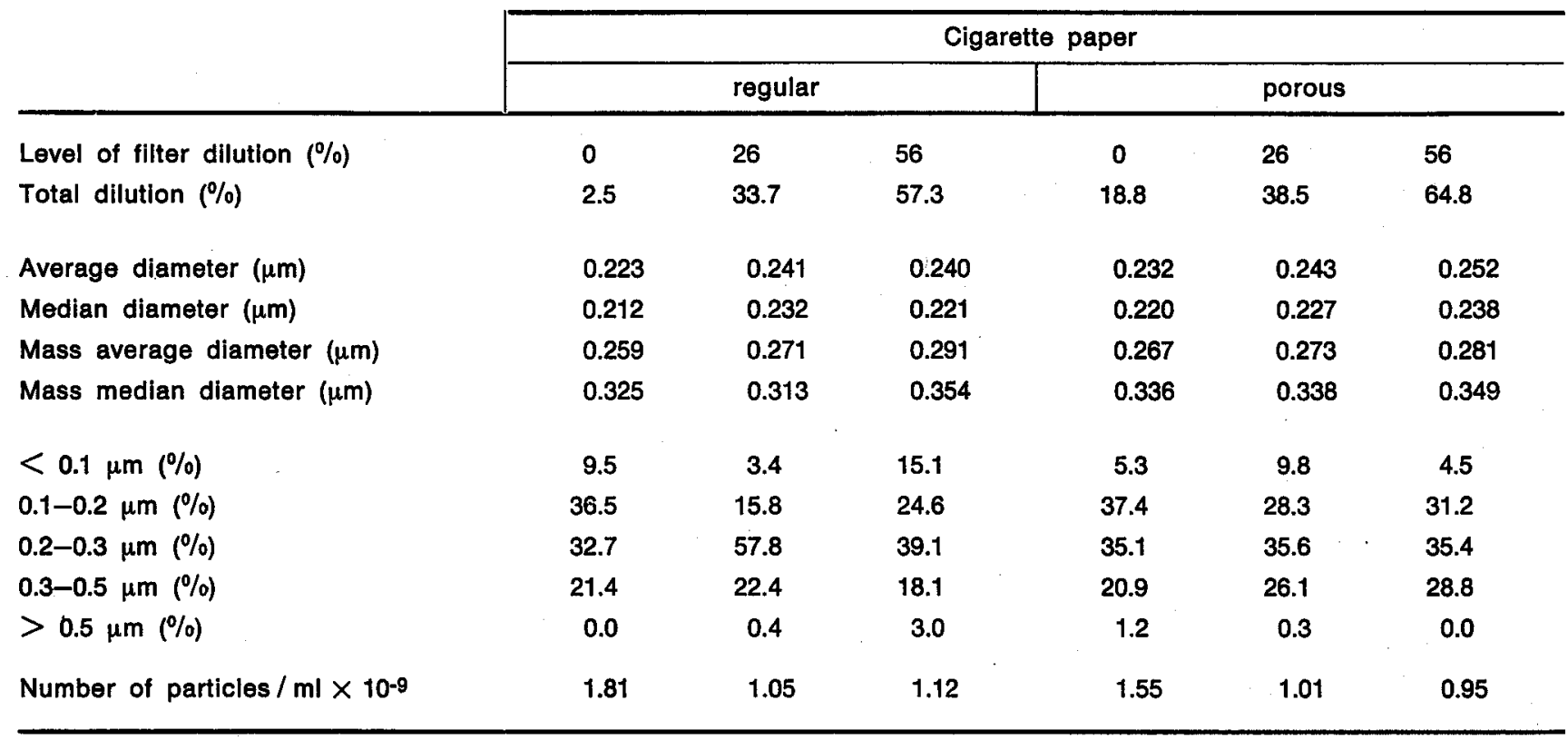


Figure 7. Effect of dilution on particle concentration.

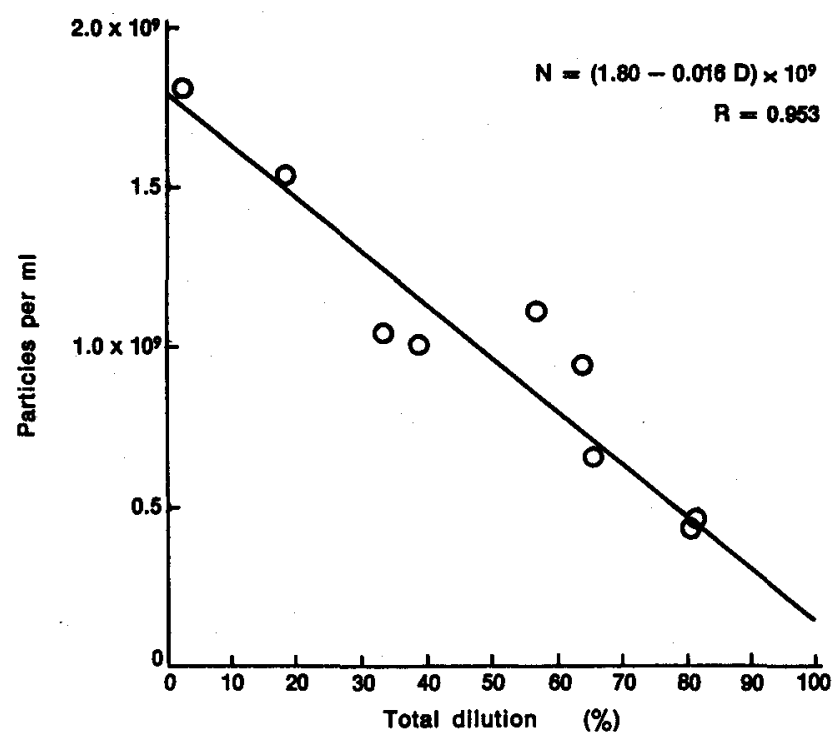

$\mathrm{N}$ : number of particles per $\mathrm{ml}, \mathrm{D}$ : total dilution.

rettes. Thus, as with filtration, dilution primarily affects the numbers of smoke particles and has less effect on the particle size distribution. Even though the size distribution effects are less dramatic, the increase in the sizes of diluted smoke may be important, as it is observed that larger particles generated by retaining smoke in the oral cavity provide an increased impact when the smoke is inhaled.

\section{CONCLUSION}

A technique for the immediate and direct fixation of smoke issuing from a burning cigarette has been devised using methyl cyanoacrylate vapor. Particle size distributions and smoke concentrations obtained by this method agree closely with those obtained by centrifugal separation (4) and light scattering methods (6). Aging studies on smoke indicate the necessity of very rapid fixation or capture of particles if realistic particle size distributions are to be obtained. Mass concentrations obtained from particle size data agree with those obtained by other means, and indicate that the particle size contribution of the methyl cyanoacrylate fixative is minimal. As has been found previously (4), the particle size distribution of fresh cigarette smoke is a relatively inflexible property of the smoke stream. Changes in the puff number, blend composition, and level of filtration and dilution have relatively little effect on the size distribution. Filtration tends to sharpen the size distribution and reduce the mean particle size while dilution tends to increase the latter quantity. The major effect of filtration and dilution is to reduce the particulate concentration, and the reductions achieved are in line with those expected from smoke analysis.

\section{SUMMARY}

To evaluate the effects of dilution and filtration on the particle size of tobacco smoke, a cyanoacrylate fixation technique has been applied directly to smoke issuing from a cigarette. This fresh, undiluted smoke has appreciable numbers of particles with diameters less than 0.1 and relatively few particles with diameters greater than 0.5 micrometer. For a middle puff on an unfiltered tobacco cigarette, the median and mass median diameters are 0.20 and 0.32 micrometer.

The experimental method involves the injection of cyanoacrylate vapor directly into the issuing smoke stream, collecting a sample of fixed particles on a membrane filter, and the use of image analysis to separate, size and count individual particles.

Table 4. Effect of high dilution levels on smoke

size dlatrlbution and concentration (4th puff, commercial brands).

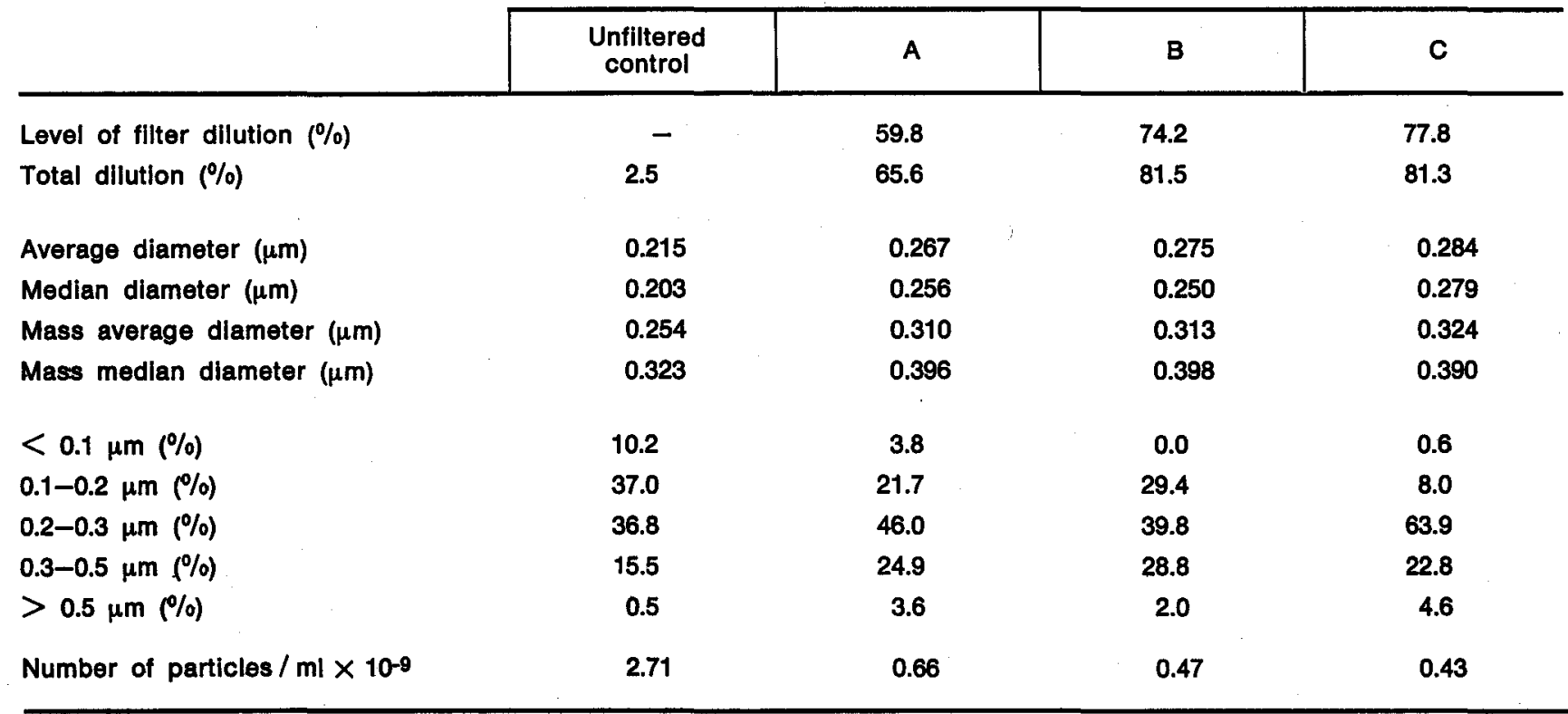


Aging of undiluted smoke for up to 1.4 seconds essentially doubles the number and mass median diameters and decreases the particulate concentration in line with coagulation theory. Different puffs on unfiltered cigarettes have little effect on the size distribution and particulate concentration. Addition of a filter removes both larger and smaller particles, and tends to skew the distribution to smaller sizes. The reduction in particulate concentration in filtered smoke is as expected from nicotine removal efficiencies. Filter dilution tends to skew the size distribution to larger sizes, while tebacco column dilution has no great effect. Particulate concentration correlates well with overall dilution levels.

\section{ZUSAMMENFASSUNG}

Zur Bestimmung der Wirkung der Verdünnung des Tabakrauches mit Luft sowie der Rauchfiltration auf die Größe der Rauchpartikel wurde ein auf Cyanacrylat basierendes Fixierungsverfahren auf Rauch angewendet, wenn dieser aus der Cigarette austritt. In dem frischen und unverdünnten Rauch befinden sich eine durchaus nennenswerte Zahl von Partikeln mit einem Durchmesser von unter 0,1 Mikrometer und verhältnismäßig wenige Partikel mit einem Durchmesser von über 0,5 Mikrometer. In einem einer filterlosen Cigarette entnommenen mittleren Zug haben die Rauchpartikel einen Mediandurdhmesser von 0,20 und einen Massen-Mediandurchmesser von 0,32 Mikrometer.

Das experimentelle Verfahren besteht darin, daß Cyanacrylat-Dampf genau in dem Augenblick in den Rauchstrom injiziert wird, wenn dieser aus der Cigarette austritt. Die auf diese Weise fixierten Partikel werden in einem Membranfilter aufgefangen, mittels Bildanalyse voneinander getrennt und einzeln gemessen und gezählt.

Die Alterung des unverdünnten Rauches um bis za 1,4 Sekunden führt entsprechend der Koagulationstheorie im wesentlichen $z \mathfrak{u}$ einer Verdoppelung des Teildhenzahlund Massen-Mediandurchmessers und zu einer Abnahme der Partikelkonzentration. Es zeigte sich, daß die Zugzahl bei filterlosen Cigaretten für die Größenverteilung und die Konzentration der Partikel von geringer Bedeutung ist. Durch den Einsatz eines Filters werden sowohl die größeren als auch die kleineren Partikel entfernt, und die Teilchengrößenverteilungskurve wird tendenziell in Richtung kleinerer Partikel verschoben. Die Verminderung der Partikelkonzentration in gefiltertem Rauch ist so, wie es der Grad der Nikotinretention erwarten läßt. Die Filterventilation verschiebt die Größenverteilung tendenziell in Richtung größerer Teilchen, während die Ventilation im Tabakstrang keinen großen Effekt hat. Die Teilchenkonzentration korreliert gut mit dem Gesamtventilationsgrad.

\section{RESUME}

On a utilisé une technique de fixation directe au cyanoacrylate sur la fumée sortant d'une cigarette pour estimer les effets de dilution et de filtration sur la taille des particules de la fumée de tabac. Cette fumée, native et non diluée, a un nombre appréciable de particules de diamètres inférieurs à $0,1 \mu \mathrm{m}$ et relativement peu de particules de diamètres supérieurs à $0,5 \mu \mathrm{m}$. Pour une bouffée moyenne d'une cigarette sans filtre, les valeurs des diamètres correspondant à leur médiane et à la médiane de la masse sont respectivement $0,20 \mu \mathrm{m}$ et $0,32 \mu \mathrm{m}$.

La méthode expérimentale implique l'injection de vapeur cyanoacrylique directement dans le courant de fumée sortant, le recueil des particules fixées sur une membrane filtrante et l'analyse d'image pour séparer, mesurer et compter chacune des particules.

Le vieillissement de la fumée non diluée jusqu'à 1,4 seconde, double essentiellement le diamètre moyen et le diamètre de la masse médiane et diminue la concentration en particules, en concordance avec la theorie de la coagulation. Des bouffées différentes sur des cigarettes sans filtre ont peu d'effet sur la distribution particulaire et la concentration. L'adjonction d'un bout-filtre élimine a la fois les plus petites et les plus grandes particules et tend à déformer la distribution du côté des particules de petite taille. La réduction de la concentration particulaire dans la fümée filtrée correspond a ce qu'on en attend selon les efficacités de rétention en nicotine. La dilution par le filtre tend à déformer la distribution vers les forts diamètres, tandis que la dilution par ventilation au niveau de la colonne de tabac n'a pas grand effet. La concentration particulaire se correlle bien avec les niveaux de dilution totale.

\section{REFERENCES}

1. Sano, K., Y. Fujitani and S. Sakata: Colloid chemistry of tobacco smokes, Distribution of size and charge of the particles; J. Chem. Soc. Japan, Pure Chem. Sec. 74 (1953) 664-668.

2. Langer, G., and M. A. Fisher: Concentration and particle size of cigarette smoke particles; Am. Med. Assoc. Arch. Ind. Health 13 (1956) 372-378.

3. Holmes, J. C., J. E. Hardcastle and R. I. Mitchell: The determination of particle size and electric darge distribution in cigarette smoke; Tob. Sci. 3 (1959) 148-153.

4. Keith, C. H., and J. C. Derridk: Measurement of the particle size distribution and concentration of cigarette smoke by the "Conifuge"; J. Colloid Sci. 15 (1960) 340-356.

5. Harris, W. J.: Size distribution of tobacco smoke by a replica method; Nature 186 (1960) 537-538.

6. Okada, T., Y. Ishizu and K. Matsunama: Determination of particle size distribution and concentration of cigarette smoke by a light scattering method; Beitr. Tabakforsch. 9 (1977) 153-160.

7. Carter, W. L., and I. Hasegawa: Fixation of tobacco smoke aerosols for size distribution studies; J. Colloid Interface Sci. 53 (1975) 134-139. 
8. Holmberg, R. W.: Determination of particle size in tobacco smoke inhalation exposure devices using methylcyanoacrylate fixation and scanning microscopy; in: Tobacco smoke inhalation bioassay chemistry, edited by M. R. Guerin, J. R. Stokely and C. E. Higgins, ORNL-5424 Report, Oak Ridge National Laboratory, Oak Ridge, Tenn., 1979, pp. 103-118.

9. Fuchs, N. A.: The mechanics of aerosols; The MacMillan Company, New York, N. Y., 1964, Chapt. VII, pp. 288-352.

10. Ped, V. G.: Deposits on cigaret filters; Applied Polymer Symposium No. 16, 1971, 19.

11. Morie, G. P., C. H. Sloan and V. G. Peck: Study of cigarette smoke filtration by means of the scanning electron microscope; Beitr. Tabakforsh. 7 (1973) 99-104.

12. Fuchs, N. A.: The mechanics of aerosols; The MacMillan Company, New York, N. Y., 1964, Chapter I, pp. 14-15.

13. ibid., Chapter VII, p. 291.

14. Adams, P. I., Coresta Dilution Task Force, data from the 1978 collaborative experiment; Imperial Tobacco Limited, Bristol, U. K., 1978.

Author's address:

Celanese Fibers Company,

Research Department,

P.O. Box 32414,

Charlotte, N.C., 28232, U.S.A. 